
stage. Journal of Education, Health and Sport. 2021;11(11):266-275. eISSN 2391-8306. DOI http://dx.doi.org/10.12775/JEHS.2021.11.11.026

https://apcz.umk.pl/JEHS/article/view/JEHS.2021.11.11.026

https://zenodo.org/record/5784321

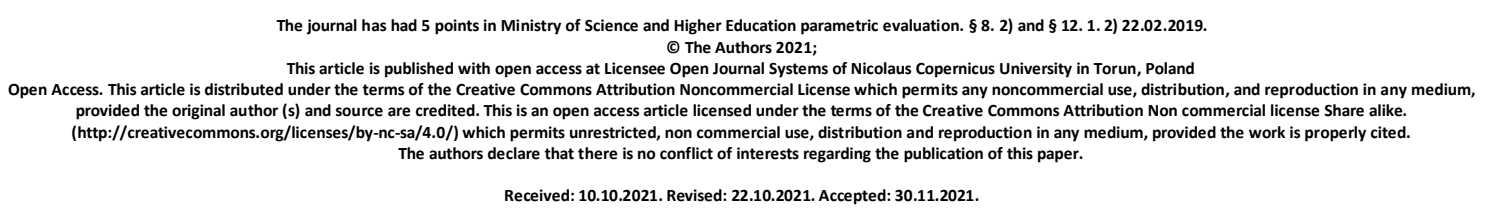

\title{
Organizational aspects of neurorehabilitation at the outpatient stage
}

\author{
D. Khramtsov ${ }^{1,2}$, Yu. Vorokhta ${ }^{1,2}$, M. Vikarenko², S. Busel ${ }^{3}$, B. Sazonov ${ }^{2}$
}

\author{
${ }^{1}$ Black Sea National University named after P. Mohyla, Ukraine \\ ${ }^{2}$ Private clinic "Expert Health", Ukraine \\ ${ }^{3}$ Odessa National Medical University, Ukraine
}

\begin{abstract}
The study was aimed to evaluate the effectiveness of IRP implementation in patients of a specialized clinic providing long-term care to neurological and neurosurgical patients.

Material and methods. The study was conducted in 2020-2021. on the basis of the MC "Expert Health" (Odessa, Ukraine). 83 patients undergoing neurorehabilitation program were examined. The correspondence of the fulfillment of key rehabilitation tasks in terms of time and quality was assessed. Additionally, the level of motivation and compliance of the patient was assessed using the MOT-Q questionnaires (for patients with previous TBI $(n=13)$, SRMS (for patients with stroke $(n=54)$ and with SRQ-E (for patients with other types of neurological pathology $(n=16)$. The overall level of compliance was assessed using the General Rehabilitation Adherence Scale (GRAS). The level of safety was assessed according to the following criteria: the presence of FAST certificates for personnel, a system for monitoring vital functions, equipment and consumables for the provision of emergency care. Statistical processing was carried out by methods of variance and correlation analysis, using the MedCalc 1.3 software.

Results. There were not recorded any significant violations of safety principles in the provision of rehabilitation assistance in the certification of personnel according to FAST. The
\end{abstract}


frequency of detecting cases of improper implementation of IRP did not exceed 6.0\% (5 cases out of 83 analyzed). When assessing the relationship between the effectiveness of IRP and the level of compliance, a strong positive correlation was found $-r=0.78$

Conclusion. 1.Provision of rehab services for neurological patients in the long term requires coordination of the actions of specialists at the intra-, inter-, and transdisciplinary levels. 2. A necessary condition for the functioning of a multidisciplinary team in the provision of rehabilitation care is certification of staff in the BLS systems - for allied health specialists and ACLS for physicians. 3. The effectiveness of IRP depends on the patient's compliance level $(r=0.78)$. 4. For the continuity of the rehabilitation process, it is necessary to involve relatives and facilitate their training in the basics of "home" rehabilitation.

\section{Key words: neurorehabilitation; effectiveness; efficacy; safety; standards}

The Law of Ukraine "On Rehabilitation in the Sphere of Health Protection" dated 03.12.2020 defines the following periods of rehabilitation: acute, subacute, long-term [1]. The goals and objectives of rehabilitation differ at each of these periods, gradually coming down to ensuring and maintaining the maximum possible independence in functional terms individually. To ensure continuity and assess the quality of rehabilitation when setting goals in the world practice of rehabilitation, the qualitative approaches of S.M.A.R.T and M.E.A.N.I.N.G. are used; as well as quantitative scales GAS (Goal attainment scale), etc. [24].

The following factors are distinguished as factors influencing the achievement of the goal (Table 1):

Table 1 Factors influencing the achievement of the goal in the rehabilitation process [1]

\begin{tabular}{|l|l|l|}
\hline \multicolumn{1}{|c|}{ Factors } & \multicolumn{1}{|c|}{ Facilitator } & \multicolumn{1}{c|}{ Barrier } \\
\hline Time & + & + \\
\hline Pain & & + \\
\hline Cognition & & + \\
\hline Family & + & + \\
\hline Medical staff & + & + \\
\hline Anxiety & & + \\
\hline Motivation & + & \\
\hline Participation & + & + \\
\hline
\end{tabular}


As can be seen from the presented table, some factors act exclusively as a barrier (the presence of pain, a change in consciousness, the presence of anxiety and / or depression). Family support, availability of time resources, sufficient staffing for the rehabilitation process, patient motivation are important for achieving the goal $[1,5]$.

The influence of the type of rehabilitation team (multidisciplinary, interdisciplinary, transdisciplinary, intradisciplinary) on the compliance of rehabilitation goals and the interaction between staff is actively discussed in the literature [6, 7].

Goal setting is the main practice of rehabilitation. Goal setting is believed to motivate the client to rehabilitate and change behavior. Nevertheless, as practice shows, both patients and doctors report difficulties in implementing an individual rehabilitation program associated with low patient motivation, technical difficulties in the interaction of members of a multidisciplinary program, as well as a lack of coordination between institutions of a rehabilitation profile [7]. Especially often, such difficulties arise in the practice of neurorehabilitation, when the patient usually has a motor or sensory deficit, and often depressive manifestations, which prevents the implementation of the tasks of restorative treatment [5]

In a study by Littooij E. et al. (2021) assessed the compliance of the stated rehabilitation goals with their real implementation in the conditions of outpatient rehabilitation centers [8]. Differences were shown in the implementation of the rehabilitation goals of patients with demyelinating diseases, stroke and cerebral palsy.

The need to maintain continuous feedback with the patient and his family members is pointed out by Borgen I et al. (2021) [9]. In their opinion, some aspects of adaptation after TBI are not sufficiently covered by the ICF classification, for example, existing approaches do not take into account problems with identity, lack of meaningful activity and a sense of loneliness in patients of this category.

In the countries of the post-Soviet space, the concept of a three-stage provision of rehabilitation medical care, which only partly corresponds to modern approaches, remains relevant. The goals of outpatient (delayed) rehabilitation are full or partial restoration of the impaired and (or) compensation for the lost functions of the affected organ or system; prevention, early diagnosis and correction of possible dysfunctions of damaged organs or body systems; prevention and reduction of the degree of possible disability; improving the quality of life; maintaining the patient's performance; social integration of the patient into society; prevention of injuries and complications (primarily contractures) [1, 10, 11]. 
PC "Expert Health" is one of the first centers in Ukraine, which provides comprehensive health care to neurological patients, including neurorehabilitation. Table 1 shows the indications for the rehabilitation of neurological and neurosurgical patients at the outpatient stage.

Table 1 Indications for rehabilitation of neurological and neurosurgical patients at the outpatient stage

\begin{tabular}{|l|l|}
\hline \multicolumn{1}{|c|}{ ICD-10 codes [12] } & \multicolumn{1}{|c|}{ Indices } \\
\hline G04, G35, G95.02, G99.2, S14.0, S24.0, S34.0 & $\begin{array}{l}\text { BI 21-90 } \\
\text { ASIA B.C,D }\end{array}$ \\
\hline B67.9, B69.0, D16.6, D32.0, D33.0-4; D35.2-4; D36.1; & BI 21-90 \\
G06.0-2; G20, G91.0-3; G93.0, G95.0; M43.1; M47.1-2; & MMT 10-30 \\
M48.0; M51.2-3; M50.0-1; M51.0-1; Q07.0; Q07.8; Q28.2- \\
3; C41.2; C70.0-1; C71, C72.0-5,8; G21, G23, G40.0-2; \\
G80.0, G93.0, G95.2,8; G97.2, I60, I61, I63, I64, S06, S14, \\
S24, T90.1-3,5; T90.8, T91.1,3; T92.4; T93.4
\end{tabular}

Regardless of what anatomical structures are involved in the pathological process when creating an individual rehabilitation program, specialists most often have to deal with the following functional disorders (Table 2).

Currently, there are few studies devoted to the organizational aspects of neurorehabilitation at the outpatient stage, and most of them consider the technical side of rehabilitation at the long-term stage $[10,11]$. At the same time, there is a clear request from domestic institutions that provide rehabilitation and palliative care in the long term for the development of approaches to the practical implementation of an individualized rehabilitation plan (IRP). 
Table 2. Functional disorders in neurological and neurosurgical patients [13]

\begin{tabular}{|c|c|}
\hline ICF & Name of category \\
\hline & $\begin{array}{l}\text { Chaprer: Mental functions ( } 10 \\
\text { categories selected out of } 22 \text { chaper } \\
\text { ategories) }\end{array}$ \\
\hline b110 & Consciousness functions \\
\hline b114 & Orientation functions \\
\hline bl 30 & Energy and drive functions \\
\hline b. 34 & Slecp functions \\
\hline b140 & Attention functions \\
\hline b147 & Psychomotor functions \\
\hline b152 & Emotional functions \\
\hline b. 156 & Perceptual functions \\
\hline b167 & Mental functions of language \\
\hline \multirow[t]{2}{*}{ b.180 } & $\begin{array}{l}\text { Experience of self and time } \\
\text { functions }\end{array}$ \\
\hline & 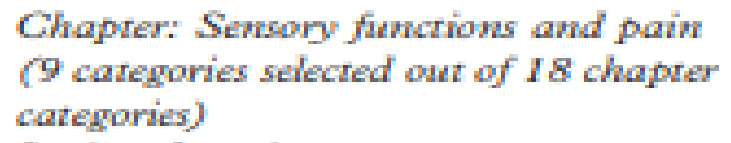 \\
\hline b210 & Secing functions \\
\hline 6215 & $\begin{array}{l}\text { Function of structures adjoining } \\
\text { the cyc }\end{array}$ \\
\hline 6230 & Hearing functions \\
\hline 6235 & Vestibular functions \\
\hline $\mathrm{b} 240$ & $\begin{array}{l}\text { Sensations associated with hearing } \\
\text { and vestibular function }\end{array}$ \\
\hline b260 & Proprioceptive function \\
\hline b265 & Touch function \\
\hline b270 & $\begin{array}{l}\text { Sensory functions related to } \\
\text { temperature and other stimuli }\end{array}$ \\
\hline 6280 & Sensation of pain \\
\hline \multirow[t]{3}{*}{$\mathrm{b} 620$} & Urination functions \\
\hline & $\begin{array}{l}\text { Chapter: Newrowascalosceleral and } \\
\text { wowewent-nelated functions }\end{array}$ \\
\hline & $\begin{array}{l}\text { (5 categories selected out of } 17 \text { chapter } \\
\text { categones) }\end{array}$ \\
\hline b7 10 & Mobility of joint functions. \\
\hline b715 & Stability of joint functions \\
\hline 6730 & Muscle power functions \\
\hline b735 & Muscle tone functions \\
\hline 6755 & $\begin{array}{l}\text { Involuntary movement reaction } \\
\text { functions }\end{array}$ \\
\hline 6760 & $\begin{array}{l}\text { Control of voluntary mowement } \\
\text { functions }\end{array}$ \\
\hline
\end{tabular}

The aim of the study was to evaluate the effectiveness of IRP implementation in patients of a specialized clinic providing long-term care to neurological and neurosurgical patients. 
Material and methods. The study was conducted in 2020-2021. on the basis of the MC "Expert Health" (Odessa, Ukraine). 83 patients undergoing neurorehabilitation program were examined. The correspondence of the fulfillment of key rehabilitation tasks in terms of time and quality was assessed. Additionally, the level of motivation and compliance of the patient was assessed using the MOT-Q questionnaires (for patients with previous TBI $(n=13)$ [14], SRMS (for patients with stroke $(\mathrm{n}=54)$ [15]) and with SRQ-E (for patients with other types of neurological pathology $(\mathrm{n}=16)$ [16] The overall level of compliance was assessed using the General Rehabilitation Adherence Scale (GRAS) [17].

In addition, the level of safety of carrying out rehabilitation measures was assessed according to the following criteria: the presence of FAST certificates for personnel, a system for monitoring vital functions, equipment and consumables for the provision of emergency care [18].

Statistical processing was carried out by methods of variance and correlation analysis, using the MedCalc 1.3 software [19]

Results

There were not recorded any significant violations of safety principles in the provision of rehabilitation assistance in the certification of personnel according to FAST. The frequency of detecting cases of improper implementation of IRP did not exceed $6.0 \%$ ( 5 cases out of 83 analyzed). The reasons were insufficient patient compliance, and in one case, the appearance of signs of bronchial obstruction (A16). Patients were generally satisfied with the level of services provided, but workers noted a lack of confidence in their knowledge and skills in providing first aid.

All workers received FAST-certified group first aid training. This program is run by the Canadian agency F.A.S.T. Rescue Inc. in collaboration with ANA, HSF, divisions of the International Red Cross, other international organizations that deal with health issues.

After the training, the number of cases of non-compliance with the IRP decreased by $50 \%$, the indicators of motivation (by 55\%) and confidence in their competencies (by $70 \%$ ) increased significantly. There were no cases falling under the category of "red" flags during the observation

As shown by the results of observations, the effectiveness of the rehabilitation program was determined by the level of the patient's motivation (Table 3 ) 
Table 3. Influence of patient motivation on the implementation of IRP

\begin{tabular}{|l|l|l|l|}
\hline \multicolumn{1}{|c|}{ Criteria } & \multicolumn{1}{|c|}{$\begin{array}{c}\text { High motivation } \\
(\mathrm{n}=21)\end{array}$} & $\begin{array}{c}\text { Moderate } \\
\text { motivation }(\mathrm{n}=60)\end{array}$ & \multicolumn{1}{c|}{$\begin{array}{c}\text { Poor motivation } \\
(\mathrm{n}=12)\end{array}$} \\
\hline $\begin{array}{l}\text { Implementation of } \\
\text { the IRP as scheduled }\end{array}$ & $100 \%$ & $80 \%$ & 41,7 \\
\hline $\begin{array}{l}\text { Deviation from } \\
\text { deadlines }\end{array}$ & - & $15 \%$ & 41,7 \\
\hline Complications & - & $5 \%$ & 16,7 \\
\hline
\end{tabular}

When assessing the relationship between the effectiveness of IRP and the level of compliance, a strong positive correlation was found $-r=0.78$ (Fig. 1)

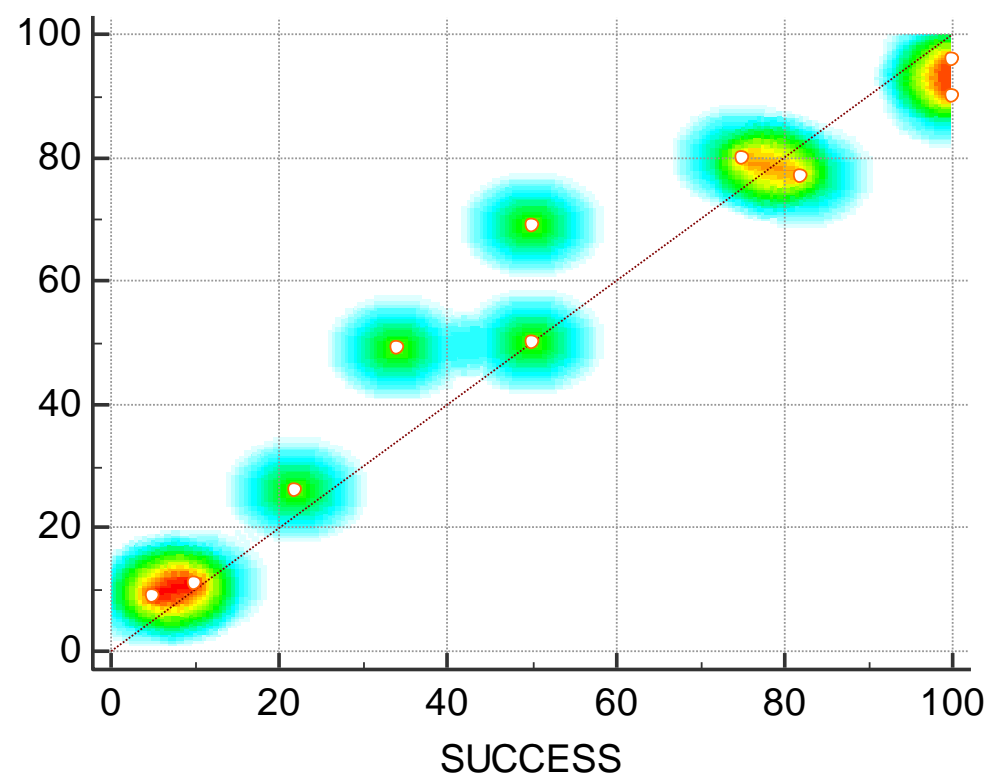

Figure 1. The role of compliance in the implementation of the IRP

There are a number of issues in the organization of outpatient neurorehabilitation, the solution of which is necessary for the successful solution of rehabilitation problems. Lack of motivation is the reason for refusal from rehabilitation or long breaks in classes, thus violating one of the basic principles of rehabilitation - "use or lose". Training for relatives and social workers helps in overcoming this obstacle. It is important to timely identify emotionalvolitional disorders and take measures to eliminate them.

In the case when a patient receives rehabilitation assistance on an outpatient basis, he needs to get to the rehabilitation center on his own, this can serve as an additional factor in reducing motivation, and can also lead to an increase in the financial costs of the family. Optimization is possible through the development of a wide network of outpatient centers and the organization of patient transportation, including with the involvement of government 
mechanisms. It is advisable to develop a methodology for teaching relatives for self-study with a patient at home.

Rehabilitation must be safe. For this, it is necessary that the specialists of the centers be able to recognize situations that threaten the health of patients. In many rehabilitation centers in Ukraine, the main staff consists of non-medical specialists: physical therapists, occupational therapists, speech therapy specialists, neuropsychologists. The way out of this situation is seen in the training of specialists under the BLS program for non-medical workers and ACLS for physicains. At the moment, there is no state standard for medical styling for rehabilitation centers. Since rehabilitation medicine in Ukraine is in its infancy, it is necessary to develop a unified state standard for certification of rehabilitation centers, including the provision of emergency medical care.

Conclusions:

1. Provision of rehab services for neurological patients in the long term requires coordination of the actions of specialists at the intra-, inter-, and transdisciplinary levels

2. A necessary condition for the functioning of a multidisciplinary team in the provision of rehabilitation care is certification of staff in the BLS systems - for allied health specialists and ACLS for physicians

3. The effectiveness of IRP depends on the patient's compliance level $(r=0.78)$

4. For the continuity of the rehabilitation process, it is necessary to involve relatives and facilitate their training in the basics of "home" rehabilitation

References.

1. "On rehabilitation in the field of health care". Law of Ukraine from 03.12.20 Retrieved from: https://zakon.rada.gov.ua/laws/show/1053-20\#Text

2. Andriy Hertsyk Purpose, goals and objectives of physical rehabilitation: a systematic approach. Retrieved from: https://evnuir.vnu.edu.ua/bitstream/123456789/11630/1/Andrey\%20Hertsik.pdf

3. Fedorenko, S.M., V.V. Vitomskyi, O.B. Lazarieva, \& M.V. Vitomska. The results of the analysis of the criteria of therapeutic alliance of patients orthopedic profile of outpatient physical therapy program. Health, sport, rehabilitation [Online], 5.3 (2019): 15-23

4. Chen P, Zanca J, Esposito E, Barrett AM. Barriers and Facilitators to Rehabilitation Care of Individuals With Spatial Neglect: A Qualitative Study of Professional Views. Arch Rehabil Res Clin Transl. 2021 Mar 31;3(2):100122. doi: 10.1016/j.arrct.2021.100122. PMID: 34179758; PMCID: PMC8212009. 
5. Charvolin L, Rippert P, Roche S, Rabilloud M, Morard MD, Marco JD, Dinomais M, Pouyfaucon M, Gimat R, Perennou D, Houx L, Iwaz J, Rode G, Vuillerot C. Determining the inter-rater reliability of the SOFMER Activity Score (version 2) for subjects in rehabilitation centers. Arch Phys Med Rehabil. 2021 Dec 7:S0003-9993(21)01633-6. doi: 10.1016/j.apmr.2021.11.005. Epub ahead of print. PMID: 34890563.

6. Durand A, D'Amours L, Giroux A, Pelletier M, Leblond J, Richards CL. Benchmarking length of stay for inpatient stroke rehabilitation without adversely affecting functional outcomes. J Rehabil Med. 2020 Oct 16;52(10):jrm00113. doi: 10.2340/165019772746. PMID: 33000174.

7. Littooij E, Doodeman S, Holla J, Ouwerkerk M, Post L, Satink T, Ter Steeg AM, Vloothuis J, Dekker J, de Groot V. Setting meaningful goals in rehabilitation: A qualitative study on the experiences of clients and clinicians in working with a practical tool. Clin Rehabil. 2021 Nov 3:2692155211046463. doi: 10.1177/02692155211046463. Epub ahead of print. PMID: 34730459.

8. Borgen IMH, Kleffelgård I, Hauger SL, Forslund MV, Søberg HL, Andelic N, Sveen U, Winter L, Løvstad M, Røe C. Patient-Reported Problem Areas in Chronic Traumatic Brain Injury. J Head Trauma Rehabil. 2021 Nov 2. doi: 10.1097/HTR.0000000000000744. Epub ahead of print. PMID: 34743086.

9. Aasdahl L, Vasseljen O, Gismervik S $\varnothing$, Johnsen R, Fimland MS. Two-Year Follow-Up of a Randomized Clinical Trial of Inpatient Multimodal Occupational Rehabilitation Vs Outpatient Acceptance and Commitment Therapy for Sick Listed Workers with Musculoskeletal or Common Mental Disorders. J Occup Rehabil. 2021 Dec;31(4):721728. doi: 10.1007/s10926-021-09969-4. Epub 2021 Mar 25. PMID: 33765241; PMCID: PMC8558177.

10. ICD-10

Retrievd

from: https://www.who.int/standards/classifications/classification-of-diseases

11. Ewert, T., Grill, E., Bartholomeyczik, S., Finger, M., Mokrusch, T., Kostanjsek, N., \& Stucki, G. (2005). ICF Core Set for patients with neurological conditions in the acute hospital. Disability and Rehabilitation, 27(7-8), 367-373.

12. Kusec A, DeMatteo C, Velikonja D, Harris JE. Psychometric properties of measures of motivation and engagement after acquired brain injury. Rehabil Psychol. 2018 Feb;63(1):92-103. doi: 10.1037/rep0000186. PMID: 29553784.

13. Roels EH, Reneman MF, Post MWM. Measurement Properties of the Full and Brief Version of the Work Rehabilitation Questionnaire in Persons with Physical Disabilities. 
J Occup Rehabil. 2021 Dec;31(4):886-894. doi: 10.1007/s10926-021-09973-8. Epub 2021 Apr 12. PMID: 33844131; PMCID: PMC8558184.

14. Uimonen M, Repo JP, Grönroos K, Häkkinen A, Walker S. Validity and reliability of the motivation for physical activity (RM4-FM) questionnaire. J Exerc Rehabil. 2021 Apr 27;17(2):103-111. doi: 10.12965/jer.2142194.097. PMID: 34012936; PMCID: PMC8103190.

15. Takura T, Hirano Goto K, Honda A. Development of a predictive model for integrated medical and long-term care resource consumption based on health behaviour: application of healthcare big data of patients with circulatory diseases. BMC Med. 2021 Jan 8;19(1):15. doi: 10.1186/s12916-020-01874-6. PMID: 33413377; PMCID: PMC7792071.

16. Certificattion program FAST. Retrieved from: https://actfast.pro

17. Medcalc software. https://www.medcalc.org/ 